analecta polit. | Vol. 10 | No. 19 | PP. 56-76

| julio-diciembre | 2020 | ISSN-e: 2390-0067 (en línea) | Medellín-Colombia

doi: http://dx.doi.org/10.18566/apolit.v10n19.a03

\title{
Panamericanismo versus latinoamericanismo: tensión geopolítica y civilizacional ${ }^{*}$
}

\author{
Panamericanism versus Latin Americanism: \\ geopolitical and civilizational tension
}

Cómo citar

este artículo en APA:

Correa, J. (2020).

Panamericanismo versus

latinoamericanismo:

tensión geopolítica y

civilizacional. Analecta

Política, 10(19), 56-76.

Fecha de recepción:

01.07.2020

Fecha de aceptación:

03.08.2020
JUAN DAVID CORREA HENAO

Magíster en Estudios en Relaciones Internacionales por la Universidad Nacional Autónoma de México (UNAM). Academia Yurupary, Colombia juan.correa@yurupary.edu.co

* Este artículo es producto de la tesis de maestría, financiada por el Consejo Nacional de Ciencia y Tecnología (CONACYT, México),. Tesis: Ser occidental o no ser occidental, he ahí el dilema: los efectos políticos de la identidad civilizacional latinoamericana. (2019) 


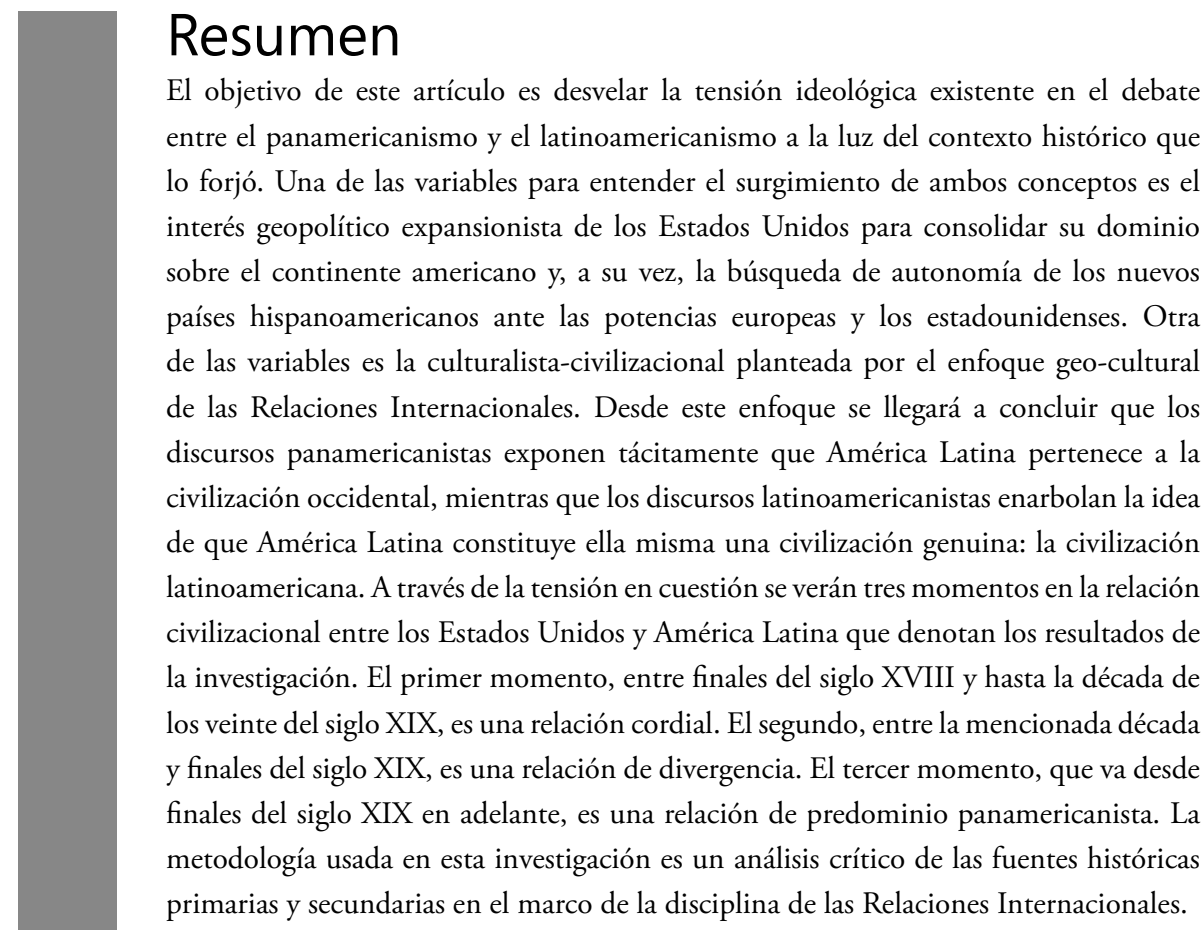

Palabras clave: América Latina, Estados Unidos, geopolítica, identidad cultural, civilización.

\section{Abstract}

The objective of this article is to reveal the ideological tension in the debate between Pan-Americanism and Latin Americanism in light of the historical context that forged it. One of the variables to understand the emergence of both concepts is the expansionist geopolitical interest of the United States to consolidate its dominance over the American continent and, in turn, the search for autonomy of the new Hispanic American countries before the European and American powers. Another variable is the culturalist-civilizational one posed by the geo-cultural approach of International Relations. From this perspective, it will be concluded that the Pan-Americanist discourses tacitly expose that Latin America belongs to Western civilization, while the Latin Americanist discourses uphold the idea that Latin America itself constitutes a genuine civilization: the Latin American civilization. Through the tension in question, we will see three moments in the civilizational relationship between the United States 


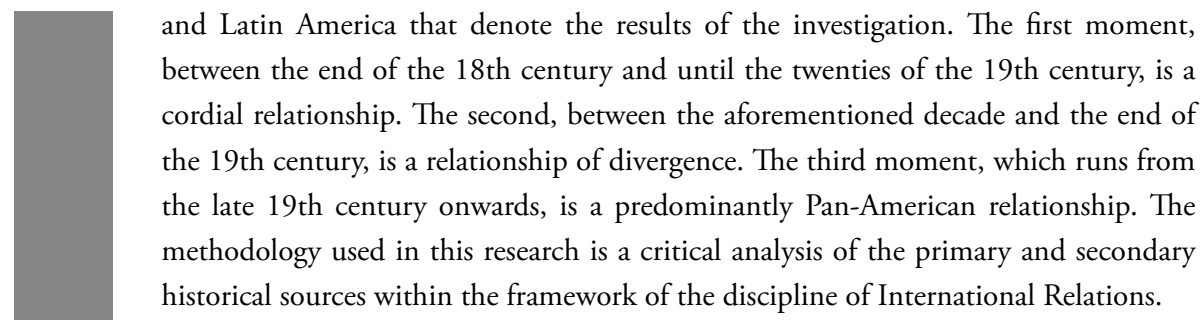

Keywords: Latin America, United States, geopolitics, cultural identity, civilization. 


\section{Introducción}

Desde finales del siglo XVIII se han vertido mares de tinta para intentar responder o simplemente elucubrar a propósito de qué es esa región que llamamos actualmente Latinoamérica, qué componentes constituyen su ser, su esencia o su ethos (Morandé, 2001) (como algunos sociólogos mencionan) y cuál es su rol dentro del continente americano.

Las respuestas han diferido de pensador en pensador y de época en época. Factores como la coyuntura histórica, los proyectos políticos, la ideología o el lugar de nacimiento han sido variables que explican estas diferencias de perspectiva. Sin embargo, hay unas coincidencias elementales en los planteamientos que han discurrido sobre esta particular cuestión: casi todos los pensadores coinciden en que existe una realidad cultural específica que abarca desde el río Bravo hasta el estrecho de Magallanes con unas características particulares. La denominación que utilizan para referirse a esta realidad o todo cultural, la filiación de esta región con Occidente y el listado de ítems que forjan su identidad o personalidad (caracterización) es lo que cambia.

También existe un consenso tácito sobre la existencia de dos ideologías contrapuestas que han colisionado desde el siglo XIX y han cimentado las relaciones internacionales ambiguas y titubeantes de la región en cuestión, a saber: el panamericanismo y el latinoamericanismo, o lo que es lo mismo, el monroismo y el bolivarismo.

Ambas ideologías, además, son apuestas geopolíticas claras, ya que reinvidicar vínculos culturales, económicos, políticos y militares más o menos estrechos entre Latinoamérica y Norteamérica (sin contar a México) depende mucho de los intereses regionales que tengan puestos los Estados de una y otra parte en coyunturas específicas.

El panamericanismo, por un lado, ha sido el proyecto estratégico utilizado por los Estados Unidos para dominar todas las relaciones hemisféricas bajo sus formas de entender la economía, la política, la cultura y la seguridad. Este país se ha servido de su poderío para hacer de todo el continente americano una misma zona homogénea y utiliza un supuesto "hermanamiento" histórico, geográfico e institucional para convencer a los líderes de la región latinoamericana de que esta unidad y protección es conveniente a sus intereses. 
Por su parte, el latinoamericanismo ha sido un proyecto intencional establecido a través de discursos proferidos por las élites políticas e intelectuales de la región para reinvindicar la unidad histórica-cultural-lingüística que tienen los Estados que a ella pertenecen y fomentar una integración política y económica que permita hacer frente a los rivales geopolíticos de la región en un momento determinado, especialmente los Estados Unidos. La identidad supranacional, desde esta perspectiva, sirve para autodeterminarse y para proteger la soberanía regional. Justo en este punto Patińo et al. (2011) dirán que la "designación de un territorio como latinoamericano ha de depender de la voluntad política del Estado y del autorreconocimiento de sus nacionales, a partir de rasgos comunes y procesos de desarrollo compartidos, que manifiesten actitudes directas de inclusión e integración regional” (p. 7).

En cualquier caso, las ideas integradoras político-culturales tienen distintos virajes, pero nacen de lógicas similares. De este modo,

cualquier propuesta de integración, sea ya una unión política total o una confederación de Estados nacionales, es inextricable de su contexto de producción y de los desafíos históricos ante los que se presenta como solución [...] "la regionalización transnacional se caracteriza por la ampliación de sus fronteras cambiantes" de cara a las peripecias ideológicas y discursivas que se manifiestan en diferentes aspectos cambiantes del pensamiento teórico sobre la integración política en América Latina. (Laucirica, 2017, p. 10)

En complemento con lo anterior y reforzando el aspecto clave de la coyuntura histórica en el cambio de discurso, Vilavoy y Maldonado (2000) afirman que "la aspiración de unir a los países de América Latina se desarrolló [...] bajo el signo de los diferentes intereses económicos y comerciales y las presiones externas de las grandes potencias en las repúblicas nacientes".

Pero el debate panamericanismo y latinoamericanismo no solo se circunscribe a los pulsos geopolíticos históricos entre las dos Américas, sino que contiene en su seno un aspecto identitario crucial: la dinámica de lo civilizacional. Cuando desde el discurso político se ha alentado la figura del "panamericanismo", se resalta la pertenencia latinoamericana a la civilización occidental, mientras que cuando se ha ventilado la idea del "latinoamericanismo" se reivindica la pertenencia de la región a otro todo cultural (civilización latinoamericana). Este dilema identitario ha causado debilidad en las relaciones internacionales de Latinoamérica. 


\section{Armonía entre las Américas}

América se consideró una misma realidad para Europa desde su "descubrimiento" y su conquista. Las denominaciones de Nuevo Mundo e Indias Occidentales designaban una misma unidad geográfica. Los distingos que se hacían giraban en torno a la pertenencia colonial existente entre una determinada metrópoli europea y una porción de territorio del continente en cuestión. Así pues, empezaron a emerger los primeros apellidos para América de acuerdo con sus dominadores: América Hispana, América Portuguesa, América Francesa, América Inglesa, América Holandesa y América Danesa.

Pese a esto los habitantes del mundo americano, fuese cual fuese, se consideraban a sí mismos americanos, en contraposición de los europeos, fuesen cuales fuesen. Si bien es cierto que categorizaciones como novohispanos, neogranadinos o rioplatenses eran utilizadas en la Colonia, pasaban a un segundo plano identitario respecto del apelativo americano. El ejemplo que patenta este asunto lo tenemos en la manera como los criollos (las élites de los virreinatos o provincias) prefieren reivindicar su condición distintiva de haber nacido en "América" en contra de los peninsulares (nacidos en Europa) más que reivindicar su identidad de ser de equis o ye provincia de España.

Por su parte, los pobladores ingleses de Norteamérica también apelaban a una identidad geográfica respecto de sus colonizadores. Ellos eran americanos con ascendencia inglesa, pero americanos, al fin y al cabo. Si bien no dejaban de reconocer su cultura anglosajona, las pugnas políticas azuzaron cada vez más la representación de ser americanos en contraposición a ser "ingleses de segunda categoría o colonizados".

Como es bien sabido, el primer país que se libertó en el continente del mundo europeo fue precisamente los Estados Unidos, entidad política surgida de la unidad de las trece colonias inglesas. La aparición de los Estados Unidos fue precoz para el contexto americano, ya que lo logró en 1776 . Al haber sido la primera colonia que se independizó y al poseer en el nombre de su país la palabra "América", los estadounidenses se arrogaron para sí el denominativo de "americanos", con lo que trastocaron el sentido identitario general que se le daba en todo el continente. A partir de la irrupción de los Estados Unidos, ellos se denominarían a sí mismos "americanos" y en otros momentos históricos nombrarían "americanos" al resto de coterráneos continentales también, lo cual creará muchas confusiones semánticas posteriormente. 
En los procesos independentistas de la América Hispana y la América Portuguesa, posteriores a la aparición de los Estados Unidos en el concierto mundial, las élites criollas siguieron fomentando la idea de que todas las provincias del continente estaban hermanadas por su deseo de liberación y por pertenecer a la misma realidad geográfica, por lo que el apelativo "americanos" los abarcaba a todos, incluso a los estadounidenses.

Antes y durante las independencias hispanoamericanas (1810-1830), los Estados Unidos se convirtieron en un faro y en una inspiración para toda la región, ya que sus ideas liberales y su constitucionalismo funcional se postularon como el deber ser desde el punto de vista de la organización política. Esto aunado a que también había tenido un pasado colonial y habitaba suelo americano.

Es bien sabido que la ayuda de los Estados Unidos a las independencias hispanoamericanas fue más intelectual que militar o material. Sin embargo, este país se convirtió en un modelo a seguir y en una suerte de "hermano mayor" incluso. Pese a esto, los nuevos dirigentes de los nacientes países hispanoamericanos también empezaron a ver el poderío de este país como una latente amenaza y a desconfiar de sus intenciones "tutelares". A partir de aquí, la imagen de los Estados Unidos para Hispanoamérica oscilará entre la admiración y el rechazo. En palabras de Zea (1971), la tensión los Estados Unidos-Hispanoamérica se puede considerar del siguiente modo:

Los Estados Unidos de Norteamérica tienen el mismo origen: colonia del Viejo Mundo, fruto de la expansión occidental. Salvo que de colonia pasan a ser colonizadores, creadores de un nuevo imperialismo hasta encabezar las fuerzas del llamado mundo occidental y convertirse en sus líderes, manteniendo su expansión y predominio, ocupando, llenando el "vacío de poder" de los viejos y ya en retirada líderes del mundo occidental, los imperialismos europeos. Este origen y el posterior desarrollo de los Estados Unidos, el paso de país colonial a país imperialista, ha dado lugar a un doble sentimiento en las relaciones de esta nación con los pueblos latinoamericanos: de admiración y de rechazo. De admiración para la nación que alcanzó su emancipación de la colonia y es un ejemplo por su capacidad de desarrollo, y, por otro, de rechazo para la nación que olvidando estos antecedentes crea un nuevo imperio, al mismo tiempo que frena las posibilidades de otros pueblos para que sigan el camino del que son gran ejemplo. Y dentro de estos Estados Unidos se da también un doble sentimiento en su relación con los pueblos latinoamericanos. Se saben ejemplo, un gran ejemplo moral, pero al mismo tiempo se saben destinados a crear un gran imperio, a encabezar el mundo del que eran instrumento para convertirse en sus líderes. Combinan esta doble 
relación considerándose no solo ejemplo a seguir, sino los guías indispensables en este camino por ellos elegido. Fácilmente hacen de su propio desarrollo la meta de todo posible desarrollo, de sus fines, los fines de los otros. Son los representantes indiscutibles del nuevo mundo creado por el Occidente, pero al mismo tiempo sus únicos beneficiarios. (p. 12)

Ejemplos de admiración y confraternidad con los estadounidenses los tenemos en principio con Francisco de Miranda y el mismo Simón Bolívar. Antes de concretarse las independencias hispanoamericanas, De Miranda (1981) se refería a los estadounidenses diciendo: "Vuestros hermanos de la América Septentrional, en número de tres millones de hombres, han llegado por su valor, sus virtudes y su perseverancia a establecer su independencia" (p. 10). Bolívar (2015a), en esta misma línea, postulaba que "en tanto nuestros compatriotas no adquieran los talentos y virtudes políticas que distinguen a nuestros hermanos del Norte, los sistemas enteramente populares, lejos de sernos favorables, temo mucho que vengan a ser nuestra ruina" (p. 170).

Pese a este sentimiento de "hermandad" con el vecino del Norte, hubo dos acciones políticas estadounidenses que empezaron a generar cierta desconfianza en el seno de los representantes de los países hispanoamericanos respecto de su liderazgo positivo en el hemisferio. Una de ellas fue el tardío reconocimiento de las primeras repúblicas hispanoamericanas que emergieron en 1819 y México en 1821. El presidente James Monroe apenas viene a declarar el reconocimiento en 1822. A propósito de este particular, el expresidente y diplomático argentino Roque Sáenz Peńa (1962) declara lo siguiente:

Los Estados Unidos, demorando el reconocimiento de las nuevas naciones, acreditaban, sin duda, su buena amistad con España, pero probaban a la América que no existía solidaridad de causa ni de principio. Se dirá que fueron los primeros en hacerlo, pero ello no acreditaría premura ni oportunidad, desde que eran los únicos que disfrutaban de capacidad legal para poderse pronunciar, mientras la Europa entera gravitaba bajo el peso de una alianza enemiga, que no podía asentir al reconocimiento; a no haber sido así, el reconocimiento hubiera tenido lugar, probablemente, con anterioridad al que nos acordaron los Estados Unidos, el año 22. (p. 192)

Y no solo fue un asunto de reconocimiento. La pasividad estadounidense en las campañas libertadoras de Hispanoamérica fue pasmosa. El mismo Bolívar (2015a) advertía que "hasta nuestros hermanos del norte se han mantenido inmóviles espectadores de esta contienda" (p. 163). 
La segunda acción que generó desconfianza en los hispanoamericanos respecto de los Estados Unidos fue la declaración de la famosa doctrina Monroe en 1823. Dicha doctrina, que cimentaría una parte fundamental de las relaciones internacionales del continente americano hasta nuestros días, se basaba en cuatro principios:

Primero. Los Estados Unidos no permitirán nuevas colonias europeas en América. Segundo. Los Estados Unidos se opondrán a las intervenciones europeas en los Estados iberoamericanos. Tercero. Los Estados Unidos no han intervenido, ni intervendrán, en las colonias europeas ya establecidas en América. Cuarto. Los Estados Unidos no intervendrán en los negocios internos de las potencias europeas. (Fabela, 1962, p. 266)

La doctrina Monroe fue un acto nacional que ni siquiera se elevó a la categoría de ley nacional. Evidentemente, un mensaje del Ejecutivo norteamericano, en el papel, no debería haber podido alterar los principios del derecho internacional de ese momento y posteriores. Pero sí los alteró: los principios de soberanía y no intervención del mundo hispanoamericano fueron quebrantados sistemáticamente por los Estados Unidos a lo largo de los suglos XIX y XX. La teoría del destino manifiesto constituyó el astrolabio moral que impulsó el ascenso de los Estados Unidos como la potencia regional primero y la potencia mundial después.

El eminente internacionalista mexicano Isidro Fabela (1962) critica retrospectivamente las "buenas intenciones" de la doctrina Monroe respecto de la libertad del mundo hispanoamericano al afirmar:

La novedad de la Doctrina consiste en que el Presidente Monroe habló en nombre de todos los Estados del Continente sin tener su representación, y se constituyó en su aparente protector, sin su consentimiento. La América española ni solicitó la declaración de Monroe, ni la ha aprobado jamás; por el contrario, la América española, al contemplar las interpretaciones egoístas y las aplicaciones atentatorias que se han dado a la Doctrina, se ha erguido en repetidas ocasiones contra ella, protestando contra esa elástica medida política, que únicamente ha servido a ciertos gobiernos de la Unión, unas veces para atacar a Europa; otras para intervenir y despojar a los países hispanoamericanos y nunca, en realidad, para efectuar un acto lealmente desinteresado. Esta parte de la doctrina Monroe es la vigente para la política norteamericana, y es la que han aplicado los Estados Unidos, dándole distintas interpretaciones, desde la aceptable de sus orígenes hasta la inmoral, injusta e ilegítima que consiste en no tolerar que Europa intervenga en Hispanoamérica para reservarse los Estados Unidos esa facultad, que de hecho han venido ejerci- 
tando impunemente en varias naciones americanas, contrariando notoriamente el pensamiento del Presidente Monroe, y transgrediendo de un modo flagrante las leyes internacionales. (p. 268)

A pesar de que a la postre se vieron nefastos resultados de la doctrina Monroe para con los intereses de Hispanoamérica y a sabiendas de estas dos acciones que propiciaban el recelo de los líderes de los nuevos países, todavía en las primeras décadas de la vida independiente de estos se contaba con el consejo, la opinión y la capacidad de los Estados Unidos, símbolo de la denominada admiración.

Simón Bolívar convocó en 1826 al Congreso Anfictiónico de Panamá para intentar crear una confederación de los países hispanoamericanos. Dicho congreso no tuvo una visión hostil frente a los Estados Unidos ni frente a la misma doctrina Monroe. De hecho, se procuraba en cierta medida darle a aquella doctrina un significado y alcances continentales con la adhesión consciente y libre de las nuevas nacionalidades. El mencionado Sáenz Peña (1962) nos comparte una cláusula de un fragmento de la invitación oficial que se le hizo a los Estados Unidos para participar en dicho congreso y la interpretación de esta:

“Tomar en consideración los medios de hacer efectiva la declaración del Presidente de los Estados Unidos (Monroe) respecto de designios ulteriores de cualquier potencia extranjera, para colonizar cualquier porción de este continente, y los medios de resistir cualquier intervención exterior en los asuntos domésticos de los gobiernos americanos”. Los móviles y propósitos de la Conferencia no podían ser más favorables a la política de los Estados Unidos; el Congreso de Panamá se proponía adherir a ella, como a un acto consumado que se quería formalizar ex post facto, y el proceder de Bolívar fue plausible. Las declaraciones de Monroe consultaban el interés de la América, y los intereses movieron la adhesión; pero la voluntad de estos Estados no había sido consultada, y la Conferencia se proponía manifestarla, homologando en las esferas internacionales, un acto irregular en sus orígenes y nacido inconsultamente en el interior de un parlamento. (p. 185)

Al final, los Estados Unidos no alentaron la iniciativa bolivariana e, incluso, no hicieron efectiva su representación, puesto que uno de sus delegados llegó tarde y enfermó, y el otro nunca llegó porque se murió en el camino. El Congreso, que se reactivó en Tacubaya (México), emitió ideas para fomentar la unidad de los pueblos hispanoamericanos y los Estados Unidos nunca las ratificó.

Bolívar estaba muy consciente de que no solo había una frontera que separaba política y estratégicamente a los norteamericanos de los hispanoamericanos, 
sino que había diferencias culturales ostensibles que hacían impracticable una comunión sincera entre los vecinos y mucho más una adaptación de las instituciones estadounidenses en el seno de los países sureños americanos. En una carta al coronel Hinton Wilson de Estados Unidos, le decía que "es desgracia que no podamos lograr la felicidad de Colombia con las leyes y costumbres de los estadounidenses. Usted sabe que esto es imposible; lo mismo que parecerse la España a la Inglaterra, y aún más todavía" (Bolívar, 1947, p. 230). En otra carta, señala Bolívar (2015b) que mejor sería para la América adoptar el Corán que el gobierno de "los Estados Unidos, aunque es el mejor del mundo. Aquí no hay que añadir más nada, sino echar la vista sobre esos pobres países de Buenos Aires, Chile, México y Guatemala [...] esos ejemplos nos dicen más que las bibliotecas" (p. 537). Incluso, el pensamiento ambivalente de Bolívar (2015c) y un tanto descreído ad portas de su muerte lo llevará a sospechar fuertemente de las intenciones estadounidenses y a afirmar que "los Estados Unidos parecen destinados por la Providencia para plagar la América de miseria a nombre de la libertad" (p. 529).

Las últimas expresiones de Bolívar nos dejan entrever que comienza a existir entre los Estados Unidos e Hispanoamérica una relación que exalta la diferencia de ambos y pone en duda la supuesta "hermandad" o "fraternidad". Se cree que con Monroe se dan los primeros visos de lo que posteriormente se denominará panamericanismo y con Bolívar los primeros visos del latinoamericanismo.

\section{La divergencia entre las dos Américas}

Las diferencias culturales influirán relevantemente a la hora de establecer vínculos estrechos entre los Estados Unidos y Latinoamérica. La actitud religiosa, los comportamientos sociales y la cultura política incidirán fuertemente en las dinámicas económicas de ambas regiones y fomentarían ciertas disparidades, por más que ambas partes sean consideradas por muchos autores como parte de la civilización occidental. No obstante, Leopoldo Zea revela que los estadounidenses se sabían los representantes más aventajados del mundo occidental y que progresaban continua y rápidamente gracias a sus valores culturales, entre ellos, el modo de vida protestante. Por su parte, los estadounidenses en general miraban en condición de inferioridad a sus vecinos del Sur, dado también por razones culturales, o bien que los vieran como occidentales de segunda categoría, o bien como otro todo civilizacional. Desde este punto de vista, Zea nos dice que el pensamiento norteamericano sobre Hispanoamérica radicaba en lo siguiente: 
Frente a esta interpretación del trabajo como cetro de la vida puritana, se alzan en sus fronteras del Sur otros pueblos. Pueblos de diversa mentalidad. Pueblos que no hacían del trabajo por el trabajo una institución moral, pueblos que respetaban la mendicidad y gustaban del ocio. Pueblos poco o nada preocupados por el dominio de la naturaleza más allá de sus más urgentes necesidades. Pueblos cuya organización social tenía sus raíces en formas de comunidad autoritaria. Pueblos que, por diversos signos, parecían alejados de las pueblos que se sabían predestinados por Dios para establecer el bien, la civilización, el progreso o la democracia. Pueblos que, al intentar organizarse a la manera de los pueblos modernos, habían fracasado rotundamente, como mostraba el caos en que habían caído al independizarse de España. Pueblos, en fin, al margen del nuevo mundo representado por Norteamérica. Pueblos fuera de la misión que se había otorgado al hombre nuevo. A pesar de todos sus esfuerzos, a pesar de la ayuda que a los mismos habían otorgado los pueblos modernos, los pueblos de la América hispana no habían logrado incorporarse al progreso. Los iberoamericanos seguían siendo inhábiles para las industrias y para las instituciones liberal-democráticas. Pueblos sin sentido práctico para la vida, retóricos, conservadores, absolutistas. Pueblos cuyos gobiernos seguían rigiéndose por los viejos moldes autoritarios de la vieja España y Portugal. En las tierras conquistadas por estos pueblos, la naturaleza seguía esperando por los hombres que arrancasen sus secretos y la pusiesen a su servicio. Los hombres no tomaban de la naturaleza otros frutos que no fuesen los que la misma le otorgaba graciosamente. (Zea, 1957, pp. 203-204)

Esta visión generalizada y generalizadora se fue consolidando poco a poco como la manera de observar a Hispanoamérica desde el Norte. No es de extrañar que esta mirada peyorativa se sincronizara con la doctrina del destino manifiesto, la cual hacía de los Estados Unidos un pueblo predestinado por Dios para dirigir, tutelar y expandirse sobre otros territorios inferiores en su capacidad para regirse personal y socialmente.

La combinación de la doctrina Monroe y la doctrina del destino manifiesto, una política y otra moral, harían que los Estados Unidos intervinieran en repetidas ocasiones en los países hispanoamericanos, que conquistaran tierras en detrimento de estos o permitieran intervenciones de potencias europeas, contrariando lo establecido por sus propios principios. La "hermandad" esbozada por norteamericanos e hispanoamericanos estaba en vilo. Es necesario enlistar las intervenciones europeas que se dieron por inacción de los Estados Unidos y las intervenciones directas que perpetraron a lo largo de los siglos XIX y XX, ya que así se dilucidará mejor la relación tensa entre el panamericanismo y el latinoamericanismo. 
En 1829, México es atacado por España, que trata de recuperar su colonia; en 1833, los ingleses ocupan las Malvinas, con la ayuda norteamericana; en 1835, los ingleses toman Belice, a pesar de que Guatemala, invocando la doctrina Monroe, pide auxilio a los Estados Unidos. En 1838 y 1849 Inglaterra y Francia combaten y hostilizan en el Río de la Plata al dictador Rosas. En 1847, los ingleses desembarcan en Nicaragua y establecen el Protectorado de La Mosquitia con la anuencia estadounidense. En 1848, los mismos ingleses, contando con la misma ayuda norteamericana, amplían su territorio en La Guayana a costa de Venezuela. En 1852, Inglaterra crea en la Bahía de Amatique, en el Mar Caribe, una nueva colonia en las hondureńas Islas de la Bahía. En 1862, España recupera Santo Domingo. El mismo año, Francia invade territorio mexicano para establecer un imperio. En 1864, una escuadra española se apodera de las Islas Chinchas en el Perú y bombardea El Callao y Valparaíso. La doctrina Monroe, en todos estos casos, brilla por su ausencia. Mientras tanto, en esta misma época, los Estados Unidos hacen su parte de la agresión a la América Latina. México desde 1831; las Malvinas en 1831; Texas y todo el norte de México desde el año 1831 al de 1847 en que México pierde la parte más grande de su territorio. Valparaíso en 1891; Puerto Rico en 1898; Cuba en 1902 y en 1933; Panamá desde 1903; La Guayra en 1908; Nicaragua en 1855, 1909, 1912 y 1924; Haití en 1914; Veracruz en 1914; Santo Domingo en 1916; Honduras en 1860 y 1924; Guatemala en 1953 y así otras veces, más o menos escandalosas. (p. 166)

En general, se piensa que 1856 es el año en que se empieza a difundir la expresión de América Latina para hacerle frente desde lo simbólico de las representaciones mentales a las realidades geopolíticas que estaban acaeciendo en el continente, a saber: las incursiones filibusteras comandadas por el estadounidense William Walker en Centroamérica. Si bien el término fue creado por el francés Michel Chevalier en 1836, la utilización por parte de personas hispanoamericanas vino a darse veinte años después. Concretamente los pioneros de la utilización del concepto de América Latina fueron el colombiano José María Torres Caicedo y el pensador chileno Francisco Bilbao. Quizá la figura del segundo tuvo más repercusión y difusión en el ámbito político que el primero, ya que presidió una importante conferencia en París ante varios ciudadanos hispanoamericanos para despertar los ánimos antiimperialistas frente a las arbitrariedades de los Estados Unidos. De esta manera,

hasta donde está averiguado, la expresión "América Latina” se inventó en 1856 para ser lanzada en son de reivindicación identitaria y de manifiesto político. Surgió con motivo de la invasión de Nicaragua por los mercenarios de William Walker, y como protesta contra la misma y también contra la potencia que, bajo 
ese disfraz, trataba de llevar a cabo un gran designio expansionista a expensas del Sur, después de haberlo logrado hacia el Oeste a expensas de México. En París fue —eso sí, y no es casual— donde brotó el término de "América Latina" del cerebro de unos latinoamericanos conscientes del peligro del Norte, conscientes de la urgencia de la unión del Sur, conscientes de la necesidad de un concepto definidor y unificador después de decenios de indecisión en la América, antes española y aún sin nombre genuino. El 22 de junio de 1856, en París, delante de más de treinta ciudadanos de casi todas las repúblicas del Sur, en un acto de repudio a la agresión a Nicaragua, el chileno Francisco Bilbao calificó de "latina" a la América que defendía y promovía y evocó "la raza latino-americana", oponiéndolas clara y únicamente a los Estados Unidos de América y al "yankee". Fechado el 26 de septiembre de 1856 y motivado por la misma y prolongada agresión, el poema Las dos Américas del colombiano, exiliado también en París, José María Torres Caicedo, las enfrenta del todo: "La raza de la América latina / Al frente tiene la sajona raza / Enemiga mortal que ya amenaza / Su libertad destruir y su pendón". Por aquellas fechas, nadie en el mundo usaba tal denominación, ni siquiera en Francia entre los adeptos de la "latinidad" incipiente. (Estrade, 1994, pp. 79-80)

Si bien ya queda esclarecido el origen del latinoamericanismo como un arma discursiva frente a las intervenciones estadounidenses en la región, emerge la incógnita de por qué el concepto de América Latina surge en 1856 y no en 1848 cuando los Estados Unidos había causado la pérdida más grande de territorio latinoamericano a expensas de México. La respuesta, nos dice Gobat (2016),

tiene mucho que ver con cuatro cambios que ocurrieron durante esos ocho ańos: el comienzo de la expansión estadounidense en ultramar, la apertura democrática de varias naciones latinoamericanas que llevó a una mayor participación de grupos no pertenecientes a las élites en la política electoral, el aplastamiento de las revoluciones liberales europeas de 1848 y la difusión transatlántica de ideologías raciales que le dieron una fuerza a la política de la blancura racial. En conjunto, estos cambios llevaron a las élites de México, Centroamérica y Sudamérica a imaginar una comunidad continental basada en la idea europea de una "raza latina", un concepto que hacía más uso de criterios culturales que raciales. Los medios impresos, como Benedict Anderson había predicho, fueron cruciales para la formación de esta entidad. Sin embargo, fue igualmente importante el papel de ciertos actores que normalmente se ignoran en los estudios de comunidades imaginadas: los diplomáticos. Gracias a sus esfuerzos por crear una alianza antiimperial entre todos los estados independientes al sur del río Bravo, una identidad racial — la raza latina - se transformó en el nombre de un continente: América Latina. (p. 65) 
Sea como fuere, el latinoamericanismo es un movimiento reactivo frente al expansionismo norteamericano. Se constituye en una bisagra entre la admiración y el rechazo que hemos referido. Es un despertar en la manera como se autopercibe la región y advierte el nuevo tipo de relaciones que deben tener las dos Américas. La búsqueda de autonomía y de igualdad es fundamental desde esta perspectiva. Nada mejor que acudir al mismo texto fundacional de Bilbao (1981) para percibir la transición de la admiración al rechazo.

Ya resuena por el mundo ese nombre de los Estados Unidos, contemporáneo de nosotros y que tan atrás nos ha dejado. Los hijos de Penn y Washington hicieron época, cuando reunidos en congreso proclamaron la más grande y bella de las constituciones existentes y aun antes de la Revolución francesa. Entonces regocijaron a la humanidad adolorida, que desde su lecho de tormento, saludó a la República del Atlántico como una profecía de la regeneración de Europa. El libre pensamiento, el self-government, la franquicia moral y la tierra abierta al emigrante, han sido las causas de su engrandecimiento y su gloria. Fueron el amparo de los que buscaban el fin de la miseria, de los que huían de la esclavitud feudal y teocrática de Europa; sirvieron de campo a las utopías, a todos los ensayos; de templo, en fin, a los que aspiran por regiones libres para sus almas libres. Ese fue el momento heroico en sus anales. Todo creció: riqueza, población, poder y libertad. Derribaron las selvas, poblaron los desiertos, recorrieron todos los mares. Despreciando tradiciones y sistemas, y creando un espíritu devorador del tiempo y espacio, han llegado a formar una nación, un genio particular. Volviendo sobre sí mismos y contemplándose tan grandes, han caído en la tentación de los titanes, creyéndose ser los árbitros de la tierra y aun los competidores del Olimpo. La personalidad infatuada desciende al individualismo, su exageración al egoísmo, y de aquí, a la injusticia y a la dureza de corazón no hay más que un paso. Pretenden en sí mismos concentrar el universo. El yankee reemplaza al americano, el patriotismo romano al de la filosofía, la industria a la caridad, la riqueza a la moral, y su propia nación a la justicia. No abolieron la esclavitud de sus estados, no conservaron las razas heroicas de sus indios, ni se han constituido en campeones de la causa universal, sino del interés americano, del individualismo sajón. Se precipitan sobre el sur, y esa nación que debía haber sido nuestra estrella, nuestro modelo, nuestra fuerza, se convierte cada día en una amenaza de la autonomía de la América del Sur. (p. 150)

Pese a lo anterior, en Latinoamérica también hubo sectores de las élites que veían con buenos ojos la doctrina Monroe y el imperialismo estadounidense, ya que podrían allanar el terreno para el progreso material y para la idónea organización política y social. Las invasiones enumeradas previamente se veían como un 
mal menor frente a la prosperidad que podría traer la influencia norteamericana. Gobat (2016), profundizando en esta idea, indica:

Algunas élites aún mantenían una percepción favorable del expansionismo es-
tadounidense, considerando que implicaba fundamentalmente la expansión del
espíritu empresarial, la tecnología y la democracia estadounidenses. Esta creencia
reflejaba la vieja idea estadounidense de un hemisferio occidental, de acuerdo con
la cual los norteamericanos y sudamericanos compartían una cultura política que
era democrática, republicana y anticolonial, construida en oposición a la tiranía,
el monarquismo y el colonialismo europeos. Esta idea de unidad hemisférica le dio
forma a la doctrina Monroe y encontró a muchos partidarios en el hemisferio sur;
estos incluían a liberales nicaragüenses, quienes justificaban su apoyo al grupo de
William Walker afirmando que ellos y los filibusteros eran "hijos de esta madre, la
América republicana". (p. 73)

Autores como Juan Bautista Alberdi y Domingo Faustino Sarmiento enarbolaban una y otra vez la admiración por los estadounidenses y decían reiteradamente que en el aprendizaje de sus prácticas y de su cultura está la llave para abrir la puerta del bienestar de los latinoamericanos. Las acciones bélicas en contra de la región por parte de la potencia las pasaban desapercibidas. Alberdi (1981) recalcaba la importancia de adaptar el pragmatismo del norteño país:

Se deja ver bien claramente que el rol de la América en los trabajos actuales de la civilización del mundo es del todo positivo y de aplicación. La abstracción pura, la metafísica en sí, no echará raíces en América. Y los Estados Unidos del Norte han hecho ver que no es verdad que sea indispensable de anterioridad un desenvolvimiento filosófico, para conseguir un desenvolvimiento político y social. Ellos han hecho un orden social nuevo y no lo han debido a la metafísica. No hay pueblo menos metafísico en el mundo que los Estados Unidos y que más materiales de especulación sugiera a los pueblos filosóficos con sus admirables adelantos prácticos. (p. 107)

Sarmiento iría aún más lejos en la idolatría hacia los Estados Unidos. Su perfección institucional y social era loable para él y veía en los norteamericanos el epítome de la civilización occidental. Habría que imitarlos para "corregir" la senda latinoamericana. Las aspiraciones de los países latinoamericanos están encarnadas en la América sajona, según el polémico pensador argentino. Dice específicamente que no basta la emancipación política de la colonia por los hábitos y costumbres que "han hecho posible el progreso del mundo occidental y que extraordinariamente encarnan los Estados Unidos. Solo este cambio haría posible 
la incorporación de América Latina en la senda del progreso, de otra forma que no fuese la de simple subordinación" (citado por Zea, 1971, p. 13). Su expresión de que seamos los "Estados Unidos de la América del Sur" deja entrever perfectamente su postura.

\section{Predominio del panamericanismo}

A finales del siglo XIX, los Estados Unidos, seguramente para congraciarse con estas élites liberales latinoamericanas que admiraban su política y economía y para renovar su deteriorada imagen frente a las élites que propendían al latinoamericanismo, lanzó una propuesta de un congreso en Washington para reunir a todos los países del continente americano. Sabiéndose el líder natural del hemisferio, convocó, entre octubre de 1889 y abril de 1890, la llamada Conferencia Internacional Americana. Dicha conferencia procuraría organizar los vínculos comerciales del resto de América con los Estados Unidos para intentar un beneficio colectivo. La integración comercial del continente, según el país convocante, se amparaba en los lazos geográficos, históricos y políticos que compartían los participantes. Los asistentes de dicha conferencia eran hermanas repúblicas (Brasil dejaría precisamente de ser imperio en noviembre de 1889) que se habían separado del yugo del Viejo Mundo y que ahora se deberían regir según su autonomía. Tener instituciones y leyes provenientes de esta civilización hacía más fácil la interacción entre los países en cuestión.

Evidentemente las intenciones encubiertas de los norteamericanos eran diáfanas: "La motivación resultó de las perentorias necesidades comerciales de Estados Unidos, cada vez más urgido de mercados exteriores seguros para los excedentes de su joven industria en expansión” (Ardao, 1986, p. 156).

Quien urdiera todo el plan para que la conferencia se llevara a cabo fue el secretario de Estado James G. Blaine, quien ya la había intentado hacer desde 1881. La importancia de este evento sería capital en la conformación ideológica de una nueva categoría para la realidad internacional de América: el panamericanismo. Este término no provino en principio de la Casa Blanca, sino que fue una expresión acuñada por la prensa estadounidense. Ya el 30 de septiembre de 1889 había cruzado el océano la expresión y el Times de Londres refería a la Conferencia como de Pan-América (p. 157). No obstante, hay autores que consideran que el mismo Blaine en persona fue el que empezó a utilizar el término recurrentemente. Kefala, citando a Arpini señala lo siguiente: 
El adjetivo "panamericana" fue utilizado por James Blaine para caracterizar la primera reunión de la Conferencia Internacional Americana, convocado por él mismo, que tuvo lugar entre octubre de 1889 y abril de 1890. Desde que Blaine ocupó la Secretaría de Estado bajo la presidencia de James A. Garfield, en 1881, adoptó una política agresiva en relación con las repúblicas de América Central y del Sur, sostenida por una renovada interpretación de la doctrina Monroe que buscaba eficiencia económica y ventajas comerciales como objetivos de una nueva política de expansión. Una de las concreciones de esa política fue la creación de la Oficina Comercial de las Repúblicas Americanas el 14 de abril de 1890 en la órbita del gobierno de Washington. En 1910 resultó bautizada con el nombre de Unión Panamericana, y se oficializó el uso del término. (citado por Kefala, 2012, p. 458)

Una vez entró en el escenario internacional el vocablo panamericanismo, comenzaron a haber facciones que se oponían a la identidad compartida que pretendía apuntalarlo, ya que lo veían como un término vacuo y carente de sentido. Evidentemente también hubo facciones que celebraron con regocijo el advenimiento de un término que describieron como afortunado. Simple y llanamente se daba inicio a la disputa filológica y semántica entre los que rechazaban o alababan el mundo estadounidense (y al mismo tiempo el mundo occidental del que proviene tal país): latinoamericanistas versus panamericanistas. Cabe decir que Latinoamérica y Panamérica "no solo significan cosas diferentes, sino que constituyen categorías sociopolíticas contrapuestas por su historia y por la carga ideológica y valorativa que cada una de ellas representa" (Kefala, 2012, p. 459).

Habría que aclarar que, mientras el panamericanismo fue alentado por muchos políticos latinoamericanos durante todo el siglo XX, el latinoamericanismo quedó confinado casi exclusivamente a la arena de los intelectuales de la región (con la importante excepción de la Comisión Económica para América Latina y el Caribe [Cepal]). El poder estadounidense redujo al latinoamericanismo de proyecto político a simple discurso culturalista que promovía la unidad de Latinoamérica sin apoyo institucional (salvo contadas excepciones posteriores, como el respaldo de Juan Domingo Perón y Getulio Vargas a esas iniciativas).

Dentro de los intelectuales que con más fiereza defendieron las premisas latinoamericanistas, tenemos al escritor uruguayo José Enrique Rodó. Es necesario mencionarlo porque en él recaerá la transición entre las ideas de integración hispanoamericana del siglo XIX y el latinoamericanismo del siglo XX. Por coincidencia, su obra seminal, el Ariel, se publica en 1900. Pero esta fecha no es casual. En 1898, los Estados Unidos habían expulsado a España de Cuba y Puerto Rico, 
y empezarían a dominar los destinos de estos dos países de ahí en adelante. Este acontecimiento generó ampolla entre todos los países latinoamericanos y, fruto de ello, se propició una identificación más fuerte con la antigua colonizadora España y se ratificó el apellido latino para la América meridional. La influencia de los Estados Unidos fue analizada desde el sentido más trascendental por Rodó, ya que no solo habla de la conquista material norteamericana, sino también de una conquista moral que está realizando el coloso del Norte y provocando la imitación. A este respecto, Zea (1971) manifiesta:

¿Porque qué es la imitación? La imitación es el reconocimiento de que lo imitado es superior a lo propio. Esto es la "América deslatinizada por propia voluntad, sin la extorsión de la conquista, y relegada luego a imagen y semejanza del arquetipo del Norte". Rodó clama en su Ariel contra lo que llama nordomanía. Esto es, contra el afán por asemejarse a una civilización, a una cultura, a un pueblo que siguiendo sus propios caminos ha dado origen a un modo de ser que no tiene por qué ser, necesariamente, el nuestro. Comprende el pensador uruguayo el afán de los pueblos latinoamericanos por recuperar el tiempo perdido, por ponerse a la altura de otros pueblos, pero siguiendo siempre sus propios caminos, no negándose a sí mismos. "No veo la gloria ni el propósito de desnaturalizar el carácter de los pueblos — su genio personal — para imponerles la identificación con un modelo extrańo al que ellos sacrifican la originalidad irremplazable de su espíritu, ni en la creencia ingenua de que eso pueda obtenerse alguna vez por procedimientos artificiales e improvisados de imitación”. (pp. 22-23)

El legado de Rodó se diseminará vastamente en toda la región latinoamericana y sus ideas engendrarán fuertes luchas contra el posicionado panamericanismo. Baste mencionar un ejemplo con Isidro Fabela, quien indicó en 1962, en plena inauguración de la sociedad internacional Acción Iberoamericana:

Nuestro ideal es el hispanoamericanismo en contraposición al panamericanismo, pues lo declaramos francamente: la política panamericanista nada práctico ha realizado en nuestro beneficio y sí en cambio, con sus reclamos nutridos y ampulosos de mutua y cariñosa estima, ha hecho creer a muchos que la Unión Panamericana de Washington y los Congresos Panamericanos son la expresión genuina de una fraternidad continental, que no existe ni puede existir mientras la llamada hermana mayor no devuelva su libertad completa a las hermanas menores que tiene sometidas. (p. 266) 
Si bien se tuvieron varias expresiones como la anterior que denotaban resquemor frente al panamericanismo, este concepto siguió gozando de buena salud, aunque habría que hacer una salvedad: en 1948 se crea la Organización de Estados Americanos (OEA) y con ello cambia la polémica denominación panamericanismo por una más fresca e incluyente: la de Interamericanismo. Aunque habría que detallar que la Secretaría General de la entidad emergente se llamaría Unión Panamericana. Fruto de la nueva organización política se empezará a ventilar fuertemente el término democrático de las Américas. Pero tanto este último como el de interamericanismo vinieron a ser camuflajes lingüísticos de los Estados Unidos para imponer su idea panamericana anclada en su poderío. Con este hito quedaría más que enterrado el latinoamericanismo, que solo volvería a emerger en un leve destello, ya en el siglo XXI, con los proyectos de las organizaciones políticas de la Alternativa Bolivariana para las Américas (ALBA) y la Unión de Naciones Suramericanas (Unasur), aunque ya supimos cuál fue el destino de ambas.

\section{Referencias}

Alberdi, J. B. (1981). Ideas para un curso de filosofía contemporánea. En R. Raymundo (Ed.), El ensayo político latinoamericano en la formación nacional. (pp. 103-110). Instituto de Capacitación Política.

Ardao, A. (1986). Panamericanismo y latinoamericanismo. En L. Zea (Comp.), América Latina en sus ideas. (pp. 157-181). Fondo de Cultura Económica.

Bilbao, F. (1981). Iniciativa de la América: idea de un congreso federal de las repúblicas. En R. Ramos (Ed.), El ensayo político latinoamericano en la formación nacional. (pp. 145-160). Instituto de Capacitación Política.

Bolívar, S. (1947). Carta al Coronel Hinton Wilson. En Autor, Obras vompletas. (pp. 225234). Lex.

Bolívar, S. (2015a). Carta de Jamaica. En Auto, Por la libertad de mi patria: discursos, cartas y decretos. (pp. 154-177). Cien de Iberoamérica.

Bolívar, S. (2015b). Carta al Gral. Daniel F. O'Leary. En Autor, Por la libertad de mi patria: discursos, cartas y decretos. (pp. 534- 541). Cien de Iberoamérica.

Bolívar, S. (2015c). Carta a Patricio Cambell. En Autor, Por la libertad de mi patria: discursos, cartas y decretos. (pp. 528-530). Cien de Iberoamérica.

Estrade, P. (1994). Observaciones a don Manuel Alvar y demás académicos sobre el uso legítimo del concepto de América Latina. Rábada, 13, 79-82.

Fabela, I. (1962). Acción iberoamericana. En VV. AA., Hispanoamérica en su lucha por su independencia. (pp. 262-270). Cuadernos Americanos.

Vilavoy, S. y Maldonado, A. (2000). Raíces históricas de la integración latinoamericana. En B. Crisorio, Historia y perspectiva de la integración latinoamericana, Asociación por la Unidad de Nuestra América, Morelia. 
76 | Juan David Correa Henao

Panamericanismo versus latinoamericanismo: tensión geopolítica y civilizacional

Gobat, M. (2016). La invención de América Latina: una historia transnacional de antiimperialismo, democracia y raza. Istor: Revista de Historia Internacional, 17(67), 61-108.

Kefala, E. (2012). "La gran América ibérica": humanismo y utopía en los años veinte: el caso de Xul Solar. Revista Canadiense de Estudios Hispánicos, 36(3), 457-479.

Laucirica, F. (2017). Los mitos de la unión latinoamericana: historia crítica del discurso de una ilusión (Tesis de doctorial, McGill University).

Miranda, F. de. (1981). Proclamación a los pueblos del continente colombiano alias Hispano-América (1801), Francisco de Miranda. En R. Ramos (Ed.), El ensayo político latinoamericano en la formación nacional. (pp. 3-15). Instituto de Capacitación Política.

Morandé, P. (2001). Ethos latinoamericano y globalización. Atenea, 484, 13-29.

Patiño Aristizábal, L. G., García Ramírez, J. D., Orozco Carmona, S. y Convers Valderrama J. P. (2011). Las relaciones internacionales de América Latina en el siglo XXI: dinámicas de un nuevo y complejo escenario. Universidad Pontificia Bolivariana.

Sáenz Peña, R. (1962). La doctrina Monroe y su evolución. En VV. AA., Hispanoamérica en su lucha por su independencia. (pp. 181-210). Cuadernos Americanos.

Zea, L. (1957). América en la Historia. Editorial Revista de Occidente.

Zea, L. (1971). Latinoamerica: emancipación y neocolonialismo: ensayos. Tiempo Nuevo. Zea, L. (1970). América en la historia. Editorial Revista de Occidente. 